\title{
Emotion-Related Socialization Behaviours in Parents of Children with an Autism Spectrum Disorder
}

\author{
Stéphanie Mazzone, Nathalie Nader-Grosbois \\ Psychological Sciences Research Institute, Chair Baron Frère in Specialized Education, Université catholique de Louvain, \\ Louvain-la-Neuve, Belgium \\ Email: nathalie.nader@uclouvain.be
}

How to cite this paper: Mazzone, S., \& Nader-Grosbois, N. (2017). Emotion-Related Socialization Behaviours in Parents of Children with an Autism Spectrum Disorder. Psychology, 8, 1134-1160. https://doi.org/10.4236/psych.2017.88074

Received: April 18, 2017

Accepted: June 13, 2017

Published: June 16, 2017

Copyright @ 2017 by authors and Scientific Research Publishing Inc. This work is licensed under the Creative Commons Attribution International License (CC BY 4.0).

http://creativecommons.org/licenses/by/4.0/

(c) † Open Access

\begin{abstract}
Eisenberg, Cumberland and Spinrad (1998) defined Emotion-Related Socialization Behaviours (ERSBs) as parents' behaviours that tend to promote their children's emotional and social abilities. They distinguish three types of ERSBs in parents: their reactions to their children's emotions, their emotion-related conversations and their emotional expressiveness. The two present studies compare these reactions (Study 1) and conversations (Study 2) in parents of children with an Autism Spectrum Disorder (ASD) and parents of typically developing (TD) children. Moreover, by applying several linear regression analyses by the stepwise method, they examined the extent to which such ERSBs vary according to individual characteristics in children and parents. Study 1 included 39 mothers and 31 fathers of ASD children and 39 mothers and 31 fathers of TD children. In Study 2, 29 mothers and 15 fathers of ASD children and 29 mothers and 15 fathers of TD children participated. For the two studies, children were matched for gender and global developmental age. Parents' ERSBs, their openness to emotional processes and children's personality were assessed by means of questionnaires. Children's developmental age was assessed using the Differential Scales of Intellectual Efficiency. For each study, we considered mothers and fathers independently in our analyses, with a view to adapt parenting programmes for each parent if necessary. Results revealed that there are few differences between the two groups of parents in their ERSBs. Regression analyses showed that the variance in ERSBs in parents of ASD children was explained partially by their openness to emotional processes and by their children's personality. Our results suggest that, although parents of ASD children are good "socializers of emotions", intervention programs should take account of the fact that their ERSBs vary according to their own emotional abilities and their children's personality. These studies emphasize the importance of identifying which in-
\end{abstract}


dividual characteristics are protective or risk factors for parent's behaviours.

\section{Keywords}

ASD Children, Parental Emotion-Related Socialization Behaviours, Openness to Emotional Processes, Children's Personality

\section{Introduction}

In daily life, in family and at school, children need to be able to display behaviours in a socially appropriate and adaptive way. It is a matter of concern to teachers and parents when children display maladjusted behaviours, particularly when they present atypical development. During the last two decades, several parental programmes have been developed in order to support social adjustment in typically developing (TD) children (e.g., Havighurst, Wilson, Harley, \& Prior, 2009) and children with atypical development (e.g., Herbert, Harvey, Roberts, Wichowski, \& Lugo-Candelas, 2013; Sanders, Mazzucchelli, \& Studman, 2004). These programmes have focused on several parenting variables, and studies have reported distinct improvements in children's emotional and social development. However, most of these programmes have taken no account of how parents' and children's characteristics may affect parenting practices. Before implementing a parental programme, it is essential to gain a better understanding of which individual characteristics could be protective or risk factors for parent's behaviours and to detect potential critical profiles in parents and/or children presenting atypical development, including children with Autism Spectrum Disorder (ASD). Based on the heuristic model of the socialization of emotions of Eisenberg, Cumberland, \& Spinrad (1998), these studies investigate whether parental Emotion-Related Socialization Behaviours (ERSBs) towards their ASD and TD children vary according to parents' and children's characteristics. Eisenberg et al. (1998) defined ERSBs as parents' behaviours that tend to promote children's emotional and social abilities. They distinguished three types of ERSBs in parents: their reactions to their children's emotions, their emotion-related conversations and their emotional expressiveness. In both these studies, we focused specifically on the way in which parents react to their children's emotions and on the way in which parents discuss emotions with their children. Several studies conducted with parents of TD children have shown that parents display more supportive reactions (e.g., helping to solve the problem that caused the child's distress) in daily life than non-supportive reactions (e.g., feeling embarrassed by an emotional display) (e.g., Eisenberg, Fabes, \& Murphy, 1996; McElwain, Halberstadt, \& Volling, 2007; Perry, Calkins, Nelson, Leerkes, \& Marcovitch, 2012). During emotion-related conversations, mothers and fathers emphasize positive and negative emotions (e.g., Lagattuta \& Wellman, 2002; Ontai \& Thompson, 2002) and they explain (e.g., Denham \& Auerbach, 1995; Garner, Dunsmore, \& Southam-Gerrow, 2008) or ask questions about the 
causes and consequences of emotions (e.g., Denham \& Auerbach, 1995; Lagattuta \& Wellman, 2002; Ruffman, Slade, \& Crowe, 2002). These studies suggest that parents who react in a supportive way and/or discuss emotions in the family may foster their children's emotional and social development, notably their Theory of Mind development (e.g., McElwain et al., 2007, Ruffman et al., 2002) or their emotional regulation (e.g., Perry et al., 2012; Shewark \& Blandon, 2015).

In the literature, surprisingly few studies have specifically examined ERSBs in parents of ASD children and compared them with those displayed by parents of TD children. Are there any distinctive characteristics in the ERSBs displayed by parents of ASD children? If there are such characteristics, what are the variables or the protective or risk factors in the process of socialization of ASD children's emotions? Given the impaired emotional development and social interaction in ASD children, it seems crucial to gain a better understanding of how the parents of these children socialize their emotions.

\subsection{ERSBs in Parents of ASD Children}

Mazzone and Nader-Grosbois (accepted) emphasized that mothers and fathers of ASD children displayed more supportive reactions than non-supportive reactions to their children's negative and positive emotions, as observed in parents of TD children (e.g., Eisenberg et al, 1996; McElwain et al., 2007; Perry et al., 2012). However, according to Bougher-Muckian, Root, Coogle, \& Floyd (2016), some differences between mothers of TD children and mothers of ASD children were reported, specifically in their response to their children's negative emotions. The mothers of ASD children displayed more supportive reactions and fewer non-supportive reactions to their children's expression of anger and fear than the mothers of TD children, who showed more distress when their children expressed anger. In addition, there were some differences between mothers and fathers of ASD children: mothers reported more encouragement and fewer minimizing responses to their children's negative emotions than fathers (Mazzone \& Nader-Grosbois, accepted). Concerning parental emotion-related conversations with ASD children, studies have focused mainly on parental discussion of mental states of emotions and desires (Kay-Raining Bird, Cleave, Curia, \& Dunleavy, 2008; Slaughter, Peterson, \& Mackintosh, 2007). In their case study, Kay-Raining Bird et al. (2008) showed that mothers used more internal state terms during everyday conversations with their ASD children than fathers. From the comparison between parents of TD children and of ASD children, Slaughter et al. (2007) emphasized that mothers of ASD children gave fewer clarifications (e.g., causal explanations) of affective mental states than mothers of TD children during a narration of a wordless picture book. However, there was no difference in the use of mental state terms and in the length of the narration.

There is a need for research to examine the profile of ERSBs in parents of ASD children, but also to explore the impact of individual factors, in order to better understand which factors lead to variation in the way parents socialize their ASD children's emotions. 


\subsection{Why It Is Relevant to Explore the Variability of Parental ERSBs According to Children's and Parents' Characteristics?}

It is important to know which individual factors affect the way in which parents react to their children's emotions or discuss emotions in order to adapt parental programmes focusing on ERSBs appropriately. Among these individual factors, parents' characteristics and children's characteristics have been highlighted as significant determinants of parenting (Belsky, 1984, 1997), and especially parents' and children's personality (e.g. Prinzie, Onghena, Hellinckx, Grietens, Ghesquière, \& Colpin, 2004). In their theoretical model, Eisenberg et al. (1998) suggested that parental ERSBs could be influenced by parents' characteristics, such as parental regulation and emotionality, and by children's characteristics, such as children's personality. Moreover, parents' cognition of their own affect and emotional wellbeing, including their ability to express and regulate their own emotions, are core characteristics of availability and responsiveness to children's emotionality (Gottman, Katz, \& Hooven, 1996, 1997; Havighurst et al., 2009).

For parents of ASD children, the majority of studies have explored children's characteristics (mainly core features of ASD) as a determinant of parenting stress or parental coping strategies (e.g., Firth \& Dryer, 2013; Peters-Scheffer, Didden, \& Korzilius, 2012). Few have focused on parenting behaviours displayed by parents of ASD children. The study of Maljaars, Boonen, Lambrechts, Van Leeuwen, \& Noens (2014) observed that parenting behaviours displayed by parents of ASD children change depending on the child's age. Some authors, using the Five Factor Model of personality to investigate the link between ASD symptomatology and personality, have revealed significant differences between ASD and TD children: ASD children have lower scores on extraversion, openness, agreeableness, emotional stability and conscientiousness (e.g., De Pauw, Mervielde, Van Leeuwen, \& De Clercq, 2011, Nader-Grosbois \& Mazzone, 2014; Rivers \& Stoneman, 2008). These significant differences in factors of personality may cause variations in parental behaviours, and notably ERSBs. We were unable to find any study that explored which factors of personality of ASD children determine parenting behaviours.

As mentioned, studies examining parental characteristics as determinants of parenting in parents of ASD children have mainly focused on stress. For example, the study of Ozturk, Riccadonna, \& Venuti (2014) showed that parents' psychological condition, especially depressive symptoms, is one of the sources of distress experienced by parents of ASD children. Given that parents' emotional well-being is an important characteristic to take into account, it might be interesting to consider their openness to emotional processes in light of their subjective representations about emotions. As parents who have poor knowledge of emotions or who feel limited by the social rules in their emotional expression will not react to their children's emotions or converse with their children about emotions in the same way as parents who feel comfortable with their own affect. Such observations would suggest that, by contrast with the model of Eisenberg et 
al. (1998), each parent's emotional expression should be considered as a parental antecedent or characteristic, and not just as a fully-fledged component in ERSBs, that creates an emotional climate in different contexts in the family (Darling \& Steinberg, 1993; Morris, Silk, Steinberg, Myers, \& Robinson, 2007). In our studies, emotional abilities in parents are considered as antecedents of ERSBs.

\subsection{Objectives of the Present Studies}

Guided by previous research conducted with typically developing children, our studies had two objectives. The first was to analyse ERSBs of parents of ASD children and to compare them with those of parents of TD children. In view of the results obtained by Bougher-Muckian et al. (2016), we expected that parents of ASD children would display more supportive ERSBs (reactions and conversations) than parents of TD children. The second objective was to explore the variability of maternal and paternal ERSBs according to parents' and ASD children's characteristics. We considered mothers and fathers independently in our analyses, to explore if there are gender differences, with a view to adapting parenting programmes for each parent if necessary. Concerning children's characteristics, we considered children's age, global developmental age and personality factors. Given the lack of previous studies conducted with parents of ASD children, it is difficult to formulate specific hypotheses but it was conjectured that children's age and/or developmental level and specific children's personality factors, such as extraversion or emotional stability, could affect parental ERSBs. For example, a parent with an ASD child with a high level of extraversion and a low level of emotional stability might display non-supportive reactions, such as minimizing responses. Regarding parents' characteristics, we took into account parents' age, level of education and factors of openness to emotional processes. As parents' emotional wellbeing is important to an appropriate response to their children's emotional needs (Havighurst et al. 2009), we expected ERSBs to vary according to specific factors of parents' openness to emotional processes. For example, parents who communicated about their own emotion would be more likely to discuss emotions with their ASD children.

\section{Study 1: Parents' Reaction to Their ASD Children's Emotions}

\subsection{Method}

Participants.

A total of 39 mothers and 31 fathers of ASD children ( 35 boys and 4 girls) and 39 mothers and 31 fathers of TD children ( 35 boys and 4 girls) participated in this study. Children were matched for gender and global developmental age. Multidisciplinary teams in psycho-medico-social centres established the ASD diagnoses. Inclusion criteria for ASD children included a diagnosis of ASD (pervasive developmental disorder-NOS, autistic disorder and Asperger's disorder), a chronological age between 3 and 12 years and a developmental age between 3 and 6 years for both verbal and non-verbal developmental age assessed 
by means of the Differential Scales of Intellectual Efficiency. Moreover, a developmental disorder diagnosis other than ASD was an exclusion criterion. TD children in this study were a subsample of an ongoing longitudinal study ( $\mathrm{n}=$ 175, Mazzone \& Nader-Grosbois, 2016). Children and their parents were recruited in French-speaking Belgian schools and specialized schools for ASD children. The educational level of parents of ASD children was as follows: primary school (3.2\% of mothers, $3.1 \%$ of fathers), secondary school $(16.1 \%$ of mothers, $25 \%$ of fathers), apprenticeship (9.7\% of mothers, $9.4 \%$ of fathers), graduate school (4-year undergraduate degree) $(45.2 \%$ of mothers, $34.4 \%$ of fathers), university level (Master's degree) (25.8\% of mothers, $28.1 \%$ of fathers). The educational level of the parents of TD children was as follows: secondary school (5.9\% of mothers, $37.1 \%$ of fathers), apprenticeship (2.9\% of fathers), graduate school (4-year undergraduate degree) ( $44.1 \%$ of mothers, $28.6 \%$ of fathers), university level (Master level) (50\% of mothers, $31.4 \%$ of fathers). Table 1 presents means and standard deviations of participants' characteristics.

Procedure.

All TD children were tested at school by experienced psychology researchers or by trained students in psychology. In each school, teachers were informed about the research project and how the children's testing would be organized. The teachers gave parents an information letter about the project and consent forms for their children's participation. In the ASD group, 70\% of the children were tested at specialized schools and 30\% were tested at home. When parents signed the consent form for their participation, the collection of data from the children, their parents and their teachers started. Parents and teachers were informed that they could withdraw from the research at any time. It was made clear that all information provided would be kept anonymous.

Measures.

Children's assessment.

Differential Scales of Intellectual Efficiency-Revised edition (EDEI-R, Perron-Borelli, 1996). Due to their validation with atypical and typical populations, these scales were used to estimate participants' global developmental age. They distinguish between verbal and non-verbal developmental age. In this study, only one verbal subscale and one non-verbal subscale were used in order to keep the children's assessment as short as possible. The "knowledge" subscale assessed children's knowledge from daily experience (e.g. "What's the colour of the milk?"). The "practical adaptation" subscale assessed children's ability to plan activity in space and time according to the objective. Concerning the scales' validation, the inter-correlations calculated between raw scores of all scales were high: they varied between .47 and .88 , half of these being up to .70 .

Questionnaires completed by parents about themselves.

Parental Reactions toward Positive and Negative Emotions (Daffe \& Nader-Grosbois, 2009). This questionnaire is an integrated and validated version of the "Coping with Children Negative Emotions Scale" (CCNES, Fabes, Poulin, Eisenberg \& Madden-Derdich, 2002, French version, Coutu, Debeau, Provost, 
Table 1. Means and standard deviations of participants' characteristics in Study 1.

\begin{tabular}{|c|c|c|c|c|c|c|}
\hline & & \multicolumn{2}{|c|}{ ASD children } & \multicolumn{2}{|c|}{ TD children } & \multirow[b]{2}{*}{$t(76)$} \\
\hline & & $M$ & SD & $M$ & $\mathrm{SD}$ & \\
\hline \multicolumn{7}{|l|}{$\begin{array}{c}\text { Children's } \\
\text { characteristics }\end{array}$} \\
\hline \multirow[t]{4}{*}{ Age (in months) } & Chronological age & 91.33 & 27.73 & 53.46 & 10.47 & $-6.912^{* * *}$ \\
\hline & Developmental age & 53.00 & 10.30 & 53.04 & 9.86 & .017 \\
\hline & $\begin{array}{l}\text { Developmental verbal } \\
\text { age }\end{array}$ & 48.41 & 15.18 & 52.53 & 14.95 & 1.208 \\
\hline & $\begin{array}{l}\text { Developmental } \\
\text { non-verbal age }\end{array}$ & 57.82 & 15.15 & 52.56 & 15.60 & -1.510 \\
\hline CARS-T & & 32.57 & 5.90 & l & l & \\
\hline \multirow[t]{5}{*}{ Personality $(\max =9)$} & Extraversion & 5.12 & 1.87 & 5.41 & 1.84 & .615 \\
\hline & Agreeableness & 5.64 & 1.43 & 6.74 & 1.32 & $3.267^{\star *}$ \\
\hline & Conscientiousness & 5.78 & 1.48 & 5.73 & 1.34 & -1.44 \\
\hline & Emotional stability & 5.44 & 1.11 & 5.80 & 1.19 & 1.268 \\
\hline & Openness & 5.68 & 1.72 & 6.70 & 1.44 & $2.582^{*}$ \\
\hline \multicolumn{7}{|l|}{$\begin{array}{c}\text { Maternal } \\
\text { characteristics }\end{array}$} \\
\hline Age (in years) & & 38.76 & 5.05 & 35.23 & 4.08 & $-3.203^{* *}$ \\
\hline \multirow{6}{*}{$\begin{array}{l}\text { Openness to } \\
\text { emotional processes } \\
(\max =4)\end{array}$} & REPCOG & 2.77 & .69 & 2.91 & .76 & .848 \\
\hline & COMEMO & 2.31 & .67 & 2.33 & .78 & .089 \\
\hline & PERINT & 2.05 & 1.02 & 2.04 & .78 & -.006 \\
\hline & PEREXT & 2.01 & .71 & 2.12 & .70 & .716 \\
\hline & REGEMO & 2.08 & .59 & 2.20 & .73 & .779 \\
\hline & RESNOR & 1.94 & 1.05 & 2.10 & .74 & .806 \\
\hline \multicolumn{7}{|l|}{$\begin{array}{c}\text { Paternal } \\
\text { characteristics }\end{array}$} \\
\hline Age (in years) & & 42.70 & 6.43 & 38.26 & 5.33 & $-3.108^{\star *}$ \\
\hline \multirow{6}{*}{$\begin{array}{l}\text { Openness to } \\
\text { emotional processes } \\
(\max =4)\end{array}$} & REPCOG & 2.64 & .58 & 2.71 & .65 & .435 \\
\hline & COMEMO & 1.57 & .65 & 1.80 & .62 & 1.441 \\
\hline & PERINT & 1.62 & .76 & 1.72 & .61 & .566 \\
\hline & PEREXT & 1.56 & .79 & 1.92 & .72 & 1.850 \\
\hline & REGEMO & 2.73 & .65 & 2.76 & .55 & .195 \\
\hline & RESNOR & 1.72 & .86 & 1.69 & .79 & -.146 \\
\hline
\end{tabular}

Notes: $\mathrm{M}=$ mean, $\mathrm{SD}=$ standard deviation, $\mathrm{ASD}=$ Autism Spectrum Disorders, $\mathrm{TD}=$ typically developing, CARS-T $=$ Childhood Autism Rating Scale, REPCOG $=$ Cognitive-Conceptual Representation of Emotions, COMEMO = Communication of Emotion, PERINT $=$ Perception of Internal Bodily Indicators of Emotions, PEREXT $=$ Perception of External Bodily Indicators of Emotions, REGEMO = Regulation of Emotion, RESNOR = Normative Restrictions of Affectivity.

Royer, \& Lavigueur, 2002) and of the "Questionnaire sur les RéactionsParentales aux Emotions Positives exprimées par l' Enfant” (QRPEPE, Ladouceur, Reid, \& Jacques, 2002). This integrated version includes 8 hypothetical scripts in which a child experiences a negative emotion (fear, sadness and anger) or a positive emo- 
tion (joy). For the negative scenarios, the six alternative parents' reactions are distress, minimizing responses, punitive responses, comforting responses, encouragement of expression of emotion and problem-focused responses. For scenarios involving joy, the four types of parents' reactions are reprimand, discomfort, socialization and encouragement (see appendix for the description of each reaction). The parent is asked to rate the probability of responding to the script in each of possible strategies when he/she experiences this situation with his/her child, using a 7-point scale ranging from "very unlikely" to "very likely".

This measure was validated on 328 parents of TD children. The factor analysis revealed two subscales (supportive reactions and non-supportive reactions) for negative and positive emotions. For the negative scenarios, Cronbach's alpha was .78 and .81, while for the joy scenarios, it was .77 and .62. The factorial structure in our ASD sample differed slightly (see "Data analysis" for the results).

Dimensions of Openness to Emotions (DOE, Reicherts, 2007). Based on the multidimensional model of affect processing, this 36 -item questionnaire assesses parents' openness to emotional processes according to their subjective representations. This measure involve six subscales. The Cognitive-Conceptual Representation of Emotions (REPCOG) subscale assesses individual knowledge of emotions and in particular the ability to differentiate affects such as emotions, moods or emotional episodes (e.g. I can accurately name every emotion or mood that I am feeling). The Communication of Emotion (COMEMO) subscale evaluates individuals' ability to express (by facial expression, voice, gestures, etc.) their emotions or to intentionally verbalized the affective state they are experiencing in order to share and communicate with others (e.g. for me, it is important to communicate to others how I am feeling). The Perception of Internal and External Bodily Indicators of Emotions (PERINT and PEREXT) subscales assess the awareness that individuals have of their internal physiological states or of external indicators generated by their emotions and affective states (e.g. In certain circumstances I recognize how I am feeling through my inner, physical reactions). The Regulation of Emotion (REGEMO) subscale evaluates individual's emotional regulation competences (e.g. I manage to calm my feelings even in difficult situations). The Normative Restrictions of Affectivity (RESNOR) subscale assesses individuals' perceptions in his emotional expression and communication by the social rules and conventions (e.g. I would like feelings to be expressed more easily in our society). The parent was asked to indicate on a 5point scale ranging to 0 ("not at all") to 4 ("completely") to what extent each item corresponded to him.

The factor analysis revealed the 6 factors corresponding to respective theoretical dimensions, with Cronbach's alpha varying between .71 and .83 .

Questionnaires completed by teachers about the children.

Childhood Autism Rating Scale (CARS, Schopler et al., 1980). This measure assesses children's behaviour in fifteen fields: impairment in human relationships, imitation, inappropriate affect, bizarre use of body movement and persistence of stereotypes, peculiarities in relation to non-human objects, resistance to 
environmental change, peculiarities of visual responsiveness, peculiarities of auditory responsiveness, near receptor responsiveness, anxiety reaction, verbal communication, non-verbal communication, activity level, intellectual functioning and general impressions of autism level. Each of the scales is scored on a continuum from 1 (normal) to 4 (severely abnormal). This questionnaire was used to obtain an estimation of the severity level of autism.

The validation of this questionnaire revealed a very good internal consistency, with Cronbach's alpha of .94 and a good inter-rater reliability $(r=.71)$.

Bipolar Rating Scales based on the Five-Factor Model (EBMCF, Roskam, De Maere-Gaudissart, \& Vandenplas-Holper, 2000). This questionnaire measures teachers' perception of children's personality. It contains 25 items, five for each factor in the model (extraversion, agreeableness, conscientiousness, emotional stability and openness). The "extraversion" factor describes children who seek contact with others as being full of energy and often experiencing positive emotions. The "agreeableness" factor corresponds to children who are inclined to be empathic and cooperative due to their optimistic view of human nature. The "conscientiousness" factor characterises children who are meticulous, careful and organized. The "emotional stability" factor corresponds to children who are stable, calm and less emotionally reactive. The "openness" factor describes children who are imaginative, curious and creative. The items take the form of pairs of adjectives (e.g., untidy-meticulous), one of which constitutes the positive pole and the other the negative pole. Teachers were asked to score children's characteristics on a 9-point scale.

The validation was conducted with $321 \mathrm{TD}$ children. The factor analysis revealed the 5 expected factors, for which Cronbach's alpha was between .70 and .93 . Coefficients of test-retest stability were highly significant and varied between .66 and .93 for teachers and between .80 and .89 for caregivers.

Data analysis.

First, we calculated inter-correlations between the study measures for the two groups separately. Then, in order to examine the differences between reactions to children's emotions of parents of ASD children and parents of TD children, several Independent-sample $t$-tests were conducted. Moreover, in order to explore the extent to which individual children's and parents' characteristics could predict the variance in the scores for parents' reactions to their ASD children's emotions, several linear regression analyses by the stepwise method were performed. As in previous studies (e.g. Durrleman, Burnel, Thommen, Foudon, Sonié, Reboul, \& Fourneret, 2016; Jahromi, Bryce, \& Swanson, 2013; Li, Zhu, Liu, \& Li, 2014; Zingerevich \& LaVesser, 2009) conducted with a small sample, the use of multiple linear regression was evaluated as a good method in light of the objectives of Study 1. Before applying these analyses, we verified in our sample the factors obtained in the study validation conducted with TD children for parental reactions to children's emotions. A single factor, "supportive reactions to children's negative emotions", including comforting, encouragement of expression of emotion and problem-focused responses, was generated for parents 
which explained $69.68 \%$ and $59.30 \%$ of the variance, with factorial loadings ranging from .77 to .89 and from .47 to .92 , for mothers and fathers respectively. Cronbach's alpha was .77 and .58 respectively. Given that the "encouragement of expression of emotion" variable reduced the factor's internal consistency for fathers, we removed this variable from the factor. A single factor, "non-supportive reactions to children's negative emotions", including distress, minimizing responses and punitive reactions, was generated for parents which explained $69.65 \%$ and $69.44 \%$ of the variance, with factorial loadings ranging from .66 to .76 and from .61 to .75 , for mothers and fathers respectively. Cronbach's alpha was .77 and .78 respectively. A single factor, "supportive reactions to children's positive emotions", including socialization and encouragement, was generated for parents which explained $54.59 \%$ and $73.69 \%$ of the variance, with factorial loadings of .74 and of .86, for mothers and fathers respectively. Cronbach's alpha was .16 and .63 respectively. As internal consistency was very low for mothers, we considered the two variables separately. A single factor, "non-supportive reactions to children's positive emotions", including reprimand and discomfort was generated for parents which explained $78.22 \%$ and $73.69 \%$ of the variance with factorial loadings of .88 and of .86 for mothers and fathers respectively. Cronbach's alpha was .72 and .63. According to the results, the factorial scores or the variables were used for the analyses.

\subsection{Results}

Preliminary analyses.

Table 2 and Table 3 present inter-correlations between parental reactions to their children's emotions and children's personality and parent's openness to emotional processes, separately for mothers and fathers, for the two groups.

Between-groups comparison of maternal and paternal reactions.

Table 4 presents the results of the Independent-samples $t$-test for the between-groups comparison. The results show that the two groups differed significantly in comforting reactions to negative emotions for both parents: mothers and fathers of ASD children presented more comforting reactions to negative emotions than mothers and fathers of TD children.

Variability of parents' reactions to their children's emotions according to parents' and children's characteristics.

We present two separate models to analyse maternal and paternal reactions. For children's characteristics, we entered children's chronological age and children's global developmental age in Step 1 and scores in the five factors of personality in Step 2. Concerning parents' characteristics, we entered parents' age and level of education in Step 3, and scores in the six factors of openness to emotional processes were added in Step 4. Items were evaluated for multicollinearity using the variance inflation index (VIF). In each group, for the two models (maternal and paternal), there was no multicollinearity between variables.

Mothers' reactions to their children's emotions. Table 5 presents the results of significant predictors of maternal reactions to children's emotions for the two groups. For the ASD group, concerning children's characteristics as predictors of 
Table 2. Spearman correlations between mothers' and fathers' reactions and parents' and children's individual characteristics for ASD sample.

\begin{tabular}{|c|c|c|c|c|c|c|c|c|c|c|c|}
\hline & \multicolumn{5}{|c|}{ Children's personality } & \multicolumn{6}{|c|}{ Openness to emotional processes } \\
\hline & $\mathrm{E}$ & A & $\mathrm{C}$ & ES & $\mathrm{O}$ & REPCOG & COMEMO & PERINT & PEREXT & REGEMO & RESNOR \\
\hline \multicolumn{12}{|l|}{ Maternal reactions } \\
\hline SUR_-E & -.222 & -.036 & .002 & -.034 & -.115 & .157 & .171 & $.554^{\star \star}$ & .173 & -.177 & $.548^{\star}$ \\
\hline Comforting & $-.362^{\star}$ & -.101 & .329 & .230 & .053 & .214 & $.437^{\star *}$ & $.622^{* * *}$ & $.504^{\star \star}$ & -.060 & $.508^{\star \star}$ \\
\hline Problem-focused & -.153 & .003 & .035 & -.138 & -.048 & .061 & -.010 & $.391^{*}$ & -.160 & .032 & $.420^{*}$ \\
\hline Encouragement & .060 & .018 & -.167 & .054 & -.122 & $.412^{*}$ & .237 & $.513^{\star *}$ & .226 & -.179 & $.470^{*}$ \\
\hline NSUR_-E & -.068 & $.421^{*}$ & .302 & .083 & .188 & -.147 & .195 & .096 & $.476^{\star *}$ & $-.532^{\star *}$ & .207 \\
\hline Distress & .045 & $.483^{\star *}$ & .148 & -.002 & .141 & -.025 & .187 & .228 & $.496^{*}$ & -.454 & .319 \\
\hline Punitive & .034 & .293 & $.406^{*}$ & .293 & .221 & .083 & $.384^{*}$ & .115 & $.560^{\star *}$ & $-.457^{\star \star}$ & .140 \\
\hline Minimizing responses & -.232 & .158 & .147 & -.109 & -.008 & $-.335^{\star}$ & -.072 & -.053 & .158 & $-.392^{\star}$ & .127 \\
\hline SUR_+E & .038 & .252 & $.389^{*}$ & .094 & .246 & .259 & $.335^{*}$ & $.346^{*}$ & $.353^{*}$ & .025 & .271 \\
\hline Socialization & .051 & .210 & -.135 & -.047 & .329 & .190 & .134 & .275 & .128 & .056 & .265 \\
\hline Encouragement & -.090 & .129 & $.648^{* * *}$ & .210 & .020 & .313 & $.402^{\star}$ & $.388^{*}$ & $.459^{* *}$ & -.070 & .254 \\
\hline NSUR_+E & -.158 & .319 & -.066 & -.066 & .013 & -.137 & -.160 & .125 & .156 & $-.713^{\star \star *}$ & .167 \\
\hline Reprimand & -.247 & $.384^{*}$ & .054 & -.116 & -.013 & -.167 & -.277 & -.213 & .073 & $-.434^{\star \star}$ & -.194 \\
\hline Discomfort & -.085 & .211 & -.146 & -.067 & .053 & -.128 & -.124 & .096 & .052 & $-.639^{* * *}$ & .136 \\
\hline \multicolumn{12}{|l|}{ Paternal reactions } \\
\hline SUR_-E & -.295 & -.352 & .216 & .216 & -.104 & .102 & .230 & .170 & $.457^{\star}$ & -.231 & .229 \\
\hline Comforting & -.280 & -.264 & .265 & .078 & .152 & -.134 & .305 & .273 & $.498^{\star *}$ & -.327 & .348 \\
\hline Problem-focused & -.139 & -.207 & .209 & .272 & .041 & .053 & .208 & .343 & $.549^{\star *}$ & -.301 & .124 \\
\hline Encouragement & -.138 & -.191 & .164 & .220 & -.216 & .292 & -.006 & -.063 & .269 & -.127 & .094 \\
\hline NSUR_-E & .081 & .075 & .035 & -.051 & .337 & -.111 & .352 & .106 & .120 & -.113 & .163 \\
\hline Distress & .126 & .076 & -.232 & -.209 & .349 & -.327 & .332 & .068 & .099 & -.274 & .074 \\
\hline Punitive & .218 & -.024 & .145 & .187 & .328 & .223 & .171 & .118 & .147 & .023 & -.062 \\
\hline Minimizing responses & -.147 & -.009 & .059 & .010 & .087 & -.040 & .324 & .055 & -.048 & .218 & .197 \\
\hline SUR_+E & .285 & .164 & -.141 & -.079 & $.361^{*}$ & .113 & -.039 & .091 & .198 & .157 & .000 \\
\hline Socialization & .192 & .179 & -.070 & .028 & $.451^{*}$ & .182 & -.248 & -.288 & $-.392^{*}$ & $.657^{* * *}$ & -.276 \\
\hline Encouragement & .117 & -.007 & -.079 & -.139 & -.052 & .129 & .084 & .177 & $.480^{* *}$ & -.275 & .138 \\
\hline NSUR_+E & .182 & -.039 & .177 & .197 & .216 & -.017 & .245 & .194 & .113 & .136 & .197 \\
\hline Reprimand & .147 & .076 & .162 & .103 & .129 & .024 & .355 & .014 & .047 & .027 & .031 \\
\hline Discomfort & .095 & .047 & .164 & .287 & .230 & .025 & .180 & .345 & .208 & .086 & $.402^{*}$ \\
\hline
\end{tabular}

Notes: $\mathrm{SUR}=$ supportive reactions, $\mathrm{NSUR}=$ non-supportive reactions, $-\mathrm{E}=$ negative emotion, $+\mathrm{E}=$ positive emotion, $\mathrm{E}=\mathrm{Extraversion}, \mathrm{A}=\mathrm{Agreeableness}$, $\mathrm{C}=$ Conscientiousness, $\mathrm{ES}=$ Emotional stability, $\mathrm{O}=$ Openness, $\mathrm{REPCOG}=$ Cognitive-Conceptual Representation of Emotions, COMEMO = Communication of Emotion, PERINT = Perception of Internal Bodily Indicators of Emotions, PEREXT = Perception of External Bodily Indicators of Emotions, REGEMO $=$ Regulation of Emotion, RESNOR $=$ Normative Restrictions of Affectivity, ${ }^{*} p .05,{ }^{* *} p<.01,{ }^{* * *} p<.001$.

maternal reactions, Model M1c showed that children's openness explained 14\% of the variance in the score for maternal socialization responses to children's positive emotions (+E). Secondly, concerning mothers' characteristics as predictors of maternal reactions, Model M3a, including mothers' level of education, perception of being limited in their emotional expressions and ability to communicate their emotions explained $49 \%$ of the variance in the score for maternal 
Table 3. Spearman correlations between mothers' and fathers' reactions and parents' and children's individual characteristics for TD sample.

\begin{tabular}{|c|c|c|c|c|c|c|c|c|c|c|c|}
\hline & \multicolumn{5}{|c|}{ Children's personality } & \multicolumn{6}{|c|}{ Openness to emotional processes } \\
\hline & $\mathrm{E}$ & A & $\mathrm{C}$ & ES & $\mathrm{O}$ & REPCOG & COMEMO & PERINT & PEREXT & REGEMO & RESNOR \\
\hline \multicolumn{12}{|l|}{ Maternal reactions } \\
\hline SUR_-E & -.222 & -.036 & .002 & -.034 & -.115 & .157 & .171 & $.554^{\star \star}$ & .173 & -.177 & $.548^{\star}$ \\
\hline Comforting & $-.362^{*}$ & -.101 & .329 & .230 & .053 & .214 & $.437^{\star *}$ & $.622^{* * *}$ & $.504^{\star \star}$ & -.060 & $.508^{* *}$ \\
\hline Problem-focused & -.153 & .003 & .035 & -.138 & -.048 & .061 & -.010 & $.391^{*}$ & -.160 & .032 & $.420^{*}$ \\
\hline Encouragement & .060 & .018 & -.167 & .054 & -.122 & $.412^{*}$ & .237 & $.513^{* *}$ & .226 & -.179 & $.470^{*}$ \\
\hline NSUR_-E & -.068 & $.421^{*}$ & .302 & .083 & .188 & -.147 & .195 & .096 & $.476^{\star *}$ & $-.532^{\star \star}$ & .207 \\
\hline Distress & .045 & $.483^{* *}$ & .148 & -.002 & .141 & -.025 & .187 & .228 & $.496^{*}$ & -.454 & .319 \\
\hline Punitive & .034 & .293 & $.406^{\star}$ & .293 & .221 & .083 & $.384^{*}$ & .115 & $.560^{* *}$ & $-.457^{\star *}$ & .140 \\
\hline Minimizing responses & -.232 & .158 & .147 & -.109 & -.008 & $-.335^{\star}$ & -.072 & -.053 & .158 & $-.392^{\star}$ & .127 \\
\hline SUR_+E & .038 & .252 & $.389^{*}$ & .094 & .246 & .259 & $.335^{\star}$ & $.346^{*}$ & $.353^{*}$ & .025 & .271 \\
\hline Socialization & .051 & .210 & -.135 & -.047 & .329 & .190 & .134 & .275 & .128 & .056 & .265 \\
\hline Encouragement & -.090 & .129 & $.648^{\star * *}$ & .210 & .020 & .313 & $.402^{*}$ & $.388^{\star}$ & $.459^{\star *}$ & -.070 & .254 \\
\hline NSUR_+E & -.158 & .319 & -.066 & -.066 & .013 & -.137 & -.160 & .125 & .156 & $-.713^{\star * \star}$ & .167 \\
\hline Reprimand & -.247 & $.384^{*}$ & .054 & -.116 & -.013 & -.167 & -.277 & -.213 & .073 & $-.434^{\star *}$ & -.194 \\
\hline Discomfort & -.085 & .211 & -.146 & -.067 & .053 & -.128 & -.124 & .096 & .052 & $-.639^{* * *}$ & .136 \\
\hline \multicolumn{12}{|l|}{ Paternal reactions } \\
\hline SUR_-E & -.295 & -.352 & .216 & .216 & -.104 & .102 & .230 & .170 & $.457^{\star}$ & -.231 & .229 \\
\hline Comforting & -.280 & -.264 & .265 & .078 & .152 & -.134 & .305 & .273 & $.498^{\star *}$ & -.327 & .348 \\
\hline Problem-focused & -.139 & -.207 & .209 & .272 & .041 & .053 & .208 & .343 & $.549^{\star *}$ & -.301 & .124 \\
\hline Encouragement & -.138 & -.191 & .164 & .220 & -.216 & .292 & -.006 & -.063 & .269 & -.127 & .094 \\
\hline NSUR_-E & .081 & .075 & .035 & -.051 & .337 & -.111 & .352 & .106 & .120 & -.113 & .163 \\
\hline Distress & .126 & .076 & -.232 & -.209 & .349 & -.327 & .332 & .068 & .099 & -.274 & .074 \\
\hline Punitive & .218 & -.024 & .145 & .187 & .328 & .223 & .171 & .118 & .147 & .023 & -.062 \\
\hline Minimizing responses & -.147 & -.009 & .059 & .010 & .087 & -.040 & .324 & .055 & -.048 & .218 & .197 \\
\hline SUR_+E & .285 & .164 & -.141 & -.079 & $.361^{\star}$ & .113 & -.039 & .091 & .198 & .157 & .000 \\
\hline Socialization & .192 & .179 & -.070 & .028 & $.451^{*}$ & .182 & -.248 & -.288 & $-.392^{*}$ & $.657^{* * *}$ & -.276 \\
\hline Encouragement & .117 & -.007 & -.079 & -.139 & -.052 & .129 & .084 & .177 & $.480^{* *}$ & -.275 & .138 \\
\hline NSUR_+E & .182 & -.039 & .177 & .197 & .216 & -.017 & .245 & .194 & .113 & .136 & .197 \\
\hline Reprimand & .147 & .076 & .162 & .103 & .129 & .024 & .355 & .014 & .047 & .027 & .031 \\
\hline Discomfort & .095 & .047 & .164 & .287 & .230 & .025 & .180 & .345 & .208 & .086 & $.402^{*}$ \\
\hline
\end{tabular}

Notes: $\mathrm{SUR}=$ supportive reactions, NSUR $=$ non-supportive reactions, $-\mathrm{E}=$ negative emotion, $+\mathrm{E}=$ positive emotion, $\mathrm{E}=$ Extraversion, $\mathrm{A}=$ Agreeableness, $\mathrm{C}=$ Conscientiousness, $\mathrm{ES}=$ Emotional stability, $\mathrm{O}=$ Openness, $\mathrm{REPCOG}=$ Cognitive-Conceptual Representation of Emotions, COMEMO $=$ Communication of Emotion, PERINT $=$ Perception of Internal Bodily Indicators of Emotions, PEREXT $=$ Perception of External Bodily Indicators of Emotions, REGEMO $=$ Regulation of Emotion, RESNOR $=$ Normative Restrictions of Affectivity, ${ }^{*} p<.05,{ }^{* *} p<.01,{ }^{* * *} p<.001$.

supportive reactions to children's negative emotions (-E). Model M1b showed that mothers' ability to regulate their emotions explained $25 \%$ of the variance in the score for maternal non-supportive reactions to children's -E. Finally, concerning the influence of both children's characteristics and mothers' characteristics on maternal reactions, Model M2d including children's conscientiousness and mother's knowledge of emotions explained $51 \%$ of the variance in the score for maternal encouragement of children's $+E$. In addition, Model M3e, including 
Table 4. Independent Sample t-test of parental reactions.

\begin{tabular}{|c|c|c|c|}
\hline & ASD children & TD children & \\
\hline & $M(\mathrm{SD})$ & $M(\mathrm{SD})$ & $t(76)$ \\
\hline \multicolumn{4}{|l|}{ Maternal reactions } \\
\hline SUR_-E & $5.12(.94)$ & $5.11(.63)$ & -.077 \\
\hline Comforting & $5.41(.94)$ & $4.87(.93)$ & $-2.576^{* *}$ \\
\hline Problem-focused & $5.51(1.09)$ & $5.74(.72)$ & 1.097 \\
\hline Encouragement & $4.43(1.35)$ & $4.71(.94)$ & 1.071 \\
\hline NSUR_-E & $2.73(.80)$ & $2.61(.47)$ & -.785 \\
\hline Distress & $2.32(.87)$ & $2.24(.57)$ & -.442 \\
\hline Punitive & $2.14(.97)$ & $1.91(.68)$ & -1.245 \\
\hline Minimizing responses & $3.72(1.06)$ & $3.69(.84)$ & -.101 \\
\hline SUR_+E & $4.74(.95)$ & $5.15(.84)$ & $1.994^{*}$ \\
\hline Socialization & $5.14(1.42)$ & $5.58(1.34)$ & 1.395 \\
\hline Encouragement & $4.35(1.13)$ & $4.72(1.16)$ & 1.435 \\
\hline NSUR_+E & $3.10(1.31)$ & $3.19(1.25)$ & .309 \\
\hline Reprimand & $3.54(1.46)$ & $3.99(1.38)$ & 1.397 \\
\hline \multirow[t]{2}{*}{ Discomfort } & $2.69(1.56)$ & $2.40(1.44)$ & -.868 \\
\hline & $M(\mathrm{SD})$ & $M(\mathrm{SD})$ & $t(60)$ \\
\hline \multicolumn{4}{|l|}{ Paternal reactions } \\
\hline SUR_-E & $4.70(.79)$ & $4.54(.82)$ & -.826 \\
\hline Comforting & $5.10(1.31)$ & $4.54(.90)$ & $-1.979^{*}$ \\
\hline Problem-focused & $5.12(.79)$ & $5.19(.97)$ & .316 \\
\hline Encouragement & $3.90(1.05)$ & $3.88(1.06)$ & -.080 \\
\hline NSUR_-E & $3.06(.78)$ & $3.04(.75)$ & -.085 \\
\hline Distress & $2.43(.89)$ & $2.43(.83)$ & .002 \\
\hline Punitive & $2.51(.96)$ & $2.36(.98)$ & -.613 \\
\hline Minimizing responses & $4.24(.94)$ & $4.33(1.14)$ & .364 \\
\hline SUR_+E & $4.90(.73)$ & $5.01(.86)$ & .555 \\
\hline Socialization & $5.32(1.17)$ & $5.52(1.23)$ & .635 \\
\hline encouragement & $4.47(1.14)$ & $4.50(1.19)$ & .109 \\
\hline NSUR_+E & $3.22(1.25)$ & $2.85(.97)$ & -1.304 \\
\hline Reprimand & $4.11(1.63)$ & $3.81(1.64)$ & -.740 \\
\hline Discomfort & $2.32(1.28)$ & $1.89(.73)$ & -1.646 \\
\hline
\end{tabular}

Notes: $\mathrm{M}=$ mean, $\mathrm{SD}=$ standard deviation, $\mathrm{SUR}=$ supportive reactions, NSUR = non-supportive reactions, $-\mathrm{E}=$ negative emotion, $+\mathrm{E}=$ positive emotion, $\mathrm{ASD}=$ Autism Spectrum Disorders, $\mathrm{TD}=$ Typically Devel oping, ${ }^{*} p<.05,{ }^{* *} p<.01$.

children's global developmental age, mothers' ability to regulate their emotions and mother's knowledge of emotions explained $40 \%$ of the variance in the score for maternal non-supportive reactions to children's $+E$. For the TD group, we obtained results for the mutual influence of children's characteristics and mothers' characteristics on maternal reactions: Model M2a, including children's agreeableness and mothers' knowledge of emotions explained $20 \%$ of the variance in the score for maternal non-supportive reactions to children's $+\mathrm{E}$.

Fathers' reactions to their ASD children's emotions. Table 6 presents the results of significant predictors of paternal reactions to their children's emotions for the two groups. For the ASD group, the results revealed that there is no significant model with children's characteristics as the sole predictors of paternal reactions. Concerning fathers' characteristics as predictors of paternal reactions, Model P1a showed that fathers' level of education explained 20\% of the variance 
Table 5. Predictors of maternal reactions to children's emotions.

\begin{tabular}{|c|c|c|c|c|c|c|c|c|c|c|c|}
\hline \multicolumn{6}{|c|}{ ASD sample } & \multicolumn{6}{|c|}{ TD sample } \\
\hline \multicolumn{12}{|c|}{ SUR_-E } \\
\hline Predictors & B & $\mathrm{SE} / \mathrm{B}$ & $\beta$ & $\mathrm{R}_{\text {adjj }}^{2}$ & $F$ & & & & & & \\
\hline Model M1a & & & & .15 & $5.264^{*}$ & & & & & & \\
\hline Level of education & .261 & .114 & $.424^{\star}$ & & & & & & & & \\
\hline Model M2a & & & & .37 & $8.193^{* *}$ & & & & & & \\
\hline Level of education & .210 & .100 & $.341^{\star}$ & & & & & & & & \\
\hline DOE_RESNOR & .397 & .130 & $.493^{\star *}$ & & & & & & & & \\
\hline Model M3a & & & & .49 & $8.966^{\star * *}$ & & & & & & \\
\hline Level of education & .135 & .094 & .220 & & & & & & & & \\
\hline DOE_RESNOR & .401 & .117 & $.498^{\star \star}$ & & & & & & & & \\
\hline DOE_COMEMO & .574 & .224 & $.386^{\star}$ & & & & & & & & \\
\hline \multicolumn{12}{|c|}{ NSUR_-E } \\
\hline Predictors & B & $\mathrm{SE} / \mathrm{B}$ & $\beta$ & $\mathrm{R}_{\text {adj }}^{2}$ & $F$ & & & & & & \\
\hline Model M1b & & & & .25 & $9.265^{* *}$ & & & & & & \\
\hline DOE_REGEMO & -.947 & .311 & $-.528^{\star *}$ & & & & & & & & \\
\hline \multicolumn{12}{|c|}{ Socialization_+E } \\
\hline Predictors & B & $\mathrm{SE} / \mathrm{B}$ & $\beta$ & $\mathrm{R}_{\text {adj }}^{2}$ & $F$ & & & & & & \\
\hline $\begin{array}{l}\text { Model M1c } \\
\text { EBMCF_O }\end{array}$ & .277 & .124 & $.415^{*}$ & .14 & $5.002^{*}$ & & & & & & \\
\hline \multicolumn{12}{|c|}{ Encouragement_+E } \\
\hline Predictors & B & $\mathrm{SE} / \mathrm{B}$ & $\beta$ & $\mathrm{R}_{\text {adj }}^{2}$ & $F$ & & & & & & \\
\hline Model M1d & & & & .40 & $17.778^{\star * *}$ & & & & & & \\
\hline EBMCF_C & .469 & .111 & $.652^{\star * \star}$ & & & & & & & & \\
\hline Model M2d & & & & .51 & $13.778^{* * *}$ & & & & & & \\
\hline EBMCF_C & .409 & .104 & $.568^{\star *}$ & & & & & & & & \\
\hline DOE_REPCOG & .679 & .276 & $.356^{*}$ & & & & & & & & \\
\hline \multicolumn{6}{|c|}{ NSUR_+E } & \multicolumn{6}{|c|}{ NSUR_+E } \\
\hline Predictors & B & $\mathrm{SE} / \mathrm{B}$ & $\beta$ & $\mathrm{R}_{\text {adj }}^{2}$ & $F$ & Predictors & B & $\mathrm{SE} / \mathrm{B}$ & $\beta$ & $\mathrm{R}_{\text {adjj }}^{2}$ & $F$ \\
\hline Model M1e & & & & .18 & $6.615^{\star}$ & & & & & & \\
\hline $\begin{array}{c}\text { GDA } \\
\text { Model M2e }\end{array}$ & .046 & .018 & $.465^{*}$ & & & Model M1a & & & & .09 & $4.188^{\star}$ \\
\hline GDA & .032 & .018 & .319 & .30 & $6.418^{* *}$ & EBMCF_A & -.333 & .163 & $-.350^{*}$ & & \\
\hline DOE REGEMO & $\begin{array}{l}.032 \\
-.678\end{array}$ & .010 & $-.404^{\star}$ & & & Model M2a & & & & .20 & $4.929^{*}$ \\
\hline Model M3e & -.070 & .300 & -.404 & & & EBMCF_A & -.314 & .153 & $-.330^{*}$ & & \\
\hline GDA & .028 & .017 & .283 & .40 & $6.552^{\star *}$ & DOE_REP & -.637 & .282 & $-.363^{\star}$ & & \\
\hline DOE_REGEMO & -.650 & .279 & $-.388^{*}$ & & & COG & & & & & \\
\hline DOE_REPCOG & -.586 & .269 & $-.340^{*}$ & & & & & & & & \\
\hline
\end{tabular}

Notes: SUR = supportive reactions, NSUR $=$ non-supportive reactions, $-\mathrm{E}=$ negative emotion, $+\mathrm{E}=$ positive emotion, $\mathrm{GDA}=\mathrm{Global}$ developmental age, $\mathrm{EBMCF}=$ Bipolar Rating Scales based on the Five Factor Model, $\mathrm{O}=$ Openness, $\mathrm{C}=$ Conscientiousness, $\mathrm{A}=\mathrm{Agreeableness}$, DOE $=\mathrm{Dimensions}$ of Openness to Emotions, REPCOG = Cognitive-Conceptual Representation of Emotions, COMEMO = Communication of Emotion, REGEMO = Regulation of Emotion, $\mathrm{RESNOR}=$ Normative Restrictions of Affectivity, ${ }^{\star} p<.05,{ }^{* *} p<.01,{ }^{* * *} p<.001$

in the score for paternal non-supportive reactions to children's -E. Model P1c showed that fathers' knowledge of emotions explained $24 \%$ of the variance in the score for paternal non-supportive reactions to children's $+\mathrm{E}$. Concerning the influence of both children's characteristics and fathers' characteristics on paternal reactions, Model P3b, including children's openness, fathers' age and knowledge 
of emotions explained $61 \%$ of the variance in the score for paternal socialization responses to children's $+\mathrm{E}$. For the TD group, no significant model emerged with the mutual influence of children's characteristics and fathers' characteristics as predictors of paternal reactions. About children's characteristics as predictors of paternal reactions, Model $\mathrm{P} 1 \mathrm{~b}$ revealed that children's global developmental age explained $29 \%$ of the variance in the score for paternal supportive reactions to children's $+\mathrm{E}$. Concerning the influence of fathers' characteristics, we observed that fathers' age explained $14 \%$ of the variance in the score for non-supportive reactions to their children's negative emotions.

\section{Study 2: Parents' Emotion-Related Conversations with Their ASD Children}

\subsection{Method}

Participants.

A total of 29 mothers and 15 fathers of ASD children ( 25 boys and 4 girls) and 29 mothers and 15 fathers of TD children ( 25 boys and 4 girls) participated in this study. Children were matched for gender and global developmental age. Inclusion and exclusion criteria for ASD children were the same as those of Study 1. TD children in this study were a subsample of an ongoing longitudinal study ( $\mathrm{n}=175$, Mazzone \& Nader-Grosbois, 2016). As with Study 1, children and their parents were recruited in French-speaking Belgian schools and specialized schools for ASD children. The educational level of parents of ASD children was

Table 6. Predictors of paternal reactions to children's emotions.

\begin{tabular}{|c|c|c|c|c|c|c|c|c|c|c|c|}
\hline \multicolumn{6}{|c|}{ ASD sample } & \multicolumn{6}{|c|}{ TD sample } \\
\hline & \multicolumn{5}{|c|}{ NSUR_-E } & \multicolumn{6}{|c|}{ NSUR_-E } \\
\hline Predictors & B & $\mathrm{SE} / \mathrm{B}$ & $\beta$ & $\mathrm{R}_{\text {adj }}^{2}$ & $F$ & Predictors & B & $\mathrm{SE} / \mathrm{B}$ & $\beta$ & $\mathrm{R}_{\text {adj }}^{2}$ & $F$ \\
\hline \multirow[t]{2}{*}{$\begin{array}{c}\text { Model P1a } \\
\text { Level of education }\end{array}$} & -.309 & .121 & $-.487^{\star}$ & .20 & $6.538^{*}$ & $\begin{array}{l}\text { Model P1a } \\
\text { Fathers' age }\end{array}$ & -.056 & .025 & $-.421^{*}$ & .14 & $4.966^{\star}$ \\
\hline & \multicolumn{5}{|c|}{ Socialization_+E } & \multicolumn{6}{|c|}{ SUR_+E (socialization and encouragement) } \\
\hline Predictors & B & $\mathrm{SE} / \mathrm{B}$ & $\beta$ & $\mathrm{R}_{\text {adj }}^{2}$ & $F$ & Predictors & B & $\mathrm{SE} / \mathrm{B}$ & $\beta$ & $\mathrm{R}_{\text {adj }}^{2}$ & $F$ \\
\hline Model P1b & & & & .25 & $7.400^{*}$ & Model P1b & & & & .29 & $10.832^{\star *}$ \\
\hline EBMCF_O & .352 & .129 & $.510^{*}$ & & & GDA & .054 & .016 & $.566^{\star \star}$ & & \\
\hline Model P2b & & & & .47 & $10.922^{* *}$ & & & & & & \\
\hline EBMCF_O & .268 & .110 & $.389^{*}$ & & & & & & & & \\
\hline Fathers' age & -.099 & .030 & $-.526^{\star \star}$ & & & & & & & & \\
\hline Model P3b & & & & .61 & $12.589^{* * *}$ & & & & & & \\
\hline EBMCF_O & .263 & .094 & $.381^{\star}$ & & & & & & & & \\
\hline Fathers' age & -.104 & .026 & $-.555^{\star *}$ & & & & & & & & \\
\hline DOE_REPCOG & -.875 & .307 & $-.380^{*}$ & & & & & & & & \\
\hline & & & NSUR_+ & & & & & & & & \\
\hline Predictors & $\mathrm{B}$ & $\mathrm{SE} / \mathrm{B}$ & $\beta$ & $\mathrm{R}_{\text {adj }}^{2}$ & $F$ & & & & & & \\
\hline $\begin{array}{c}\text { Model P1c } \\
\text { DOE_REPCOG }\end{array}$ & -.956 & .343 & $-.520^{\star}$ & .24 & $7.771^{\star}$ & & & & & & \\
\hline
\end{tabular}

Notes: NSUR = non-supportive reactions, $-\mathrm{E}=$ negative emotion, $+\mathrm{E}=$ positive emotion, GDA = Global developmental age, EBMCF = Bipolar Rating Scales based on the Five Factor Model, $\mathrm{O}=$ Openness, DOE = Dimensions of Openness to Emotions, REPCOG = Cognitive-Conceptual Representation of Emotions, ${ }^{*} p<.05,{ }^{* *} p<.01,{ }^{* * *} p<.001$. 
as follows: secondary school (20.8\% of mothers, $23.1 \%$ of fathers), apprenticeship (12.5\% of mothers, $15.4 \%$ of fathers), graduate school (4-year undergraduate degree) (41.7\% of mothers, $23.1 \%$ of fathers), university level (Master's degree) (25\% of mothers, $38.5 \%$ of fathers). The educational level of the parents of TD children was as follows: secondary school (3.7\% of mothers, $14.3 \%$ of fathers), apprenticeship (7.1\% of fathers), graduate school (4-year undergraduate degree) $(51.9 \%$ of mothers, $35.7 \%$ of fathers), university level (Master's degree (44.4\% of mothers, $42.9 \%$ of fathers). Table 7 presents means and standard deviations of participants' characteristics.

Table 7. Means and standard deviations of participants' characteristics in Study 2.

\begin{tabular}{|c|c|c|c|c|c|c|}
\hline & & \multicolumn{2}{|c|}{ ASD children } & \multicolumn{2}{|c|}{ TD children } & \multirow[b]{2}{*}{$t(56)$} \\
\hline & & $M$ & SD & $M$ & $\mathrm{SD}$ & \\
\hline \multicolumn{7}{|l|}{ Children's characteristics } \\
\hline \multirow[t]{5}{*}{ Age (in months) } & Chronological age & 89.59 & 26.57 & 53.58 & 9.33 & $-6.973^{\star \star *}$ \\
\hline & Developmental age & 52.38 & 10.27 & 52.47 & 10.06 & .032 \\
\hline & Developmental verbal age & 48.34 & 15.76 & 49.27 & 14.10 & .235 \\
\hline & Developmental non-verbal age & 56.45 & 14.43 & 54.24 & 16.51 & \\
\hline & & 32.44 & 5.46 & l & I & -.542 \\
\hline \multirow[t]{5}{*}{ Personality $(\max =9)$} & Extraversion & 5.25 & 2.00 & 5.09 & 1.94 & -.285 \\
\hline & Agreeableness & 5.88 & 1.17 & 6.75 & 1.15 & $2.629^{*}$ \\
\hline & Conscientiousness & 5.67 & 1.57 & 5.73 & 1.38 & .158 \\
\hline & Emotional stability & 5.26 & 1.04 & 5.99 & 1.08 & $2.392^{*}$ \\
\hline & Openness & 5.79 & 1.77 & 6.46 & 1.54 & 1.432 \\
\hline \multicolumn{7}{|l|}{ Maternal characteristics } \\
\hline Age (in years) & & 38.08 & 5.12 & 35.25 & 4.17 & $-.231^{*}$ \\
\hline \multirow[t]{6}{*}{ Openness to emotional processes $(\max =4)$} & REPCOG & 2.69 & .73 & 2.87 & .79 & .869 \\
\hline & COMEMO & 2.29 & .71 & 2.25 & .78 & -.201 \\
\hline & PERINT & 2.08 & .71 & 2.07 & .82 & -.007 \\
\hline & PEREXT & 2.03 & .99 & 2.08 & .72 & .262 \\
\hline & REGEMO & 2.05 & .74 & 2.09 & .75 & .238 \\
\hline & RESNOR & 1.96 & .60 & 1.97 & .68 & .057 \\
\hline \multicolumn{7}{|l|}{ Paternal characteristics } \\
\hline Age (in years) & & 44.23 & 9.19 & 38.36 & 6.06 & $-1.976^{\star}$ \\
\hline \multirow[t]{6}{*}{ Openness to emotional processes $(\max =4)$} & REPCOG & 2.75 & .58 & 2.80 & .61 & .249 \\
\hline & COMEMO & 1.48 & .76 & 1.81 & .65 & 1.292 \\
\hline & PERINT & 2.01 & .66 & 1.81 & .63 & -.837 \\
\hline & PEREXT & 1.77 & .82 & 2.09 & .62 & 1.211 \\
\hline & REGEMO & 2.66 & .71 & 2.78 & .55 & .526 \\
\hline & RESNOR & 1.72 & .91 & 1.89 & .82 & .526 \\
\hline
\end{tabular}

Notes: $\mathrm{M}=$ mean, $\mathrm{SD}=$ standard deviation, $\mathrm{ASD}=$ Autism Spectrum Disorders, $\mathrm{TD}=$ typically developing, CARS-T = Childhood Autism Rating Scale, REPCOG $=$ Cognitive-Conceptual Representation of Emotions, COMEMO $=$ Communication of Emotion, PERINT $=$ Perception of Internal Bodily Indicators of Emotions, PEREXT $=$ Perception of External Bodily Indicators of Emotions, REGEMO = Regulation of Emotion, RESNOR = Normative Restrictions of Affectivity. 
Procedure.

The procedure was the same as for Study 1.

Measures.

Participants' global developmental age was estimated with the Differential Scales of Intellectual Efficiency-Revised edition (EDEI-R, Perron-Borelli, 1996), as described for Study 1.

Parent-Child emotion-related conversations were assessed using the Questionnaire of Parent-Child Conversations about Emotions (QPCCE, Mazzone, Roskam, Mikolajczak, \& Nader-Grosbois, 2017). In the "Preliminary questions part", parents respond to three questions assessing the place of the emotional field in the family. First question: "As a parent, expressing your feelings is not at all important... very important". Second question: "As a parent, helping your child to express his/her feelings in everyday life is not at all important... very important". Parents were asked to place a vertical mark on a continuum from "not important at all" to "very important". Third question: "Please indicate how you rank the following areas in your parenting by entering the numbers from 1 to 5 in the box ( 1 being the highest priority and 5 being the lowest priority): intellectual and learning, adaptive, emotional, social and motor". The first part of the QPCCE consists of 24 items assessing emotion-related conversations between parents and their children relating to supportive (20 items) and nonsupportive ( 4 items) strategies. Using a 4 -point scale ranging from " 0 time" to " 5 times and more", parents indicate the number of times they have experienced the situation with their children during the last two weeks. We also provided a "not appropriate" response option which could be used if the situation had not arisen during the last two weeks. The second part of the questionnaire presents a listing of emotional terms for the four basic emotions (joy, sadness, anger and fear) (Kotsou, 2009; Labounty et al., 2008). Parents are asked to mark all terms that they usually use with their children.

This measure was validated on 300 parents of TD children. The factor analysis revealed a single factor with reversed items for the non-supportive strategies. Cronbach's alpha for the total score was .91. The factorial structure obtained in our ASD sample was the same (see "Data analysis" for the results) as in the study validation.

Parents' openness to emotional processes was assessed using the Dimensions of Openness to Emotions (DOE, Reicherts, 2007) questionnaire described for Study 1.

Children's personality was assessed using the Bipolar Rating Scales based on the Five-Factor Model (EBMCF, Roskam, De Maere-Gaudissart, \& VandenplasHolper, 2000) described for Study 1.

Data analysis.

First, we calculated inter-correlations between the study measures for the two groups separately. Then, in order to examine the differences between emotionrelated conversations in parents of ASD children and in parents of TD children, Independent samples $t$-tests were conducted. Moreover, in order to explore the 
extent to which individual children's and parents' characteristics could predict the variance in the scores for emotion-related conversations in parents of ASD children, as for Study 1, several linear regression analyses by the stepwise method were performed. Before applying these analyses, we verified in our sample the internal consistency for the factor obtained in the study validation conducted with TD children for parental emotion-related conversations. Cronbach's alpha was .93 and .88 for mothers and fathers respectively.

\subsection{Results}

Preliminary analyses.

Table 8 presents inter-correlations between the study measures in ASD and TD children, independently for mothers and fathers.

Between-groups comparison of maternal and paternal emotion-related conversations.

The Independent samples $t$-test for the between-groups comparison revealed no differences for maternal emotion-related conversations $\left(M_{\mathrm{TD}}=2.57, \mathrm{SD}_{\mathrm{TD}}\right.$ $\left.=.40 ; M_{\mathrm{ASD}}=2.52, \mathrm{SD}_{\mathrm{ASD}}=.60 ; t(48.953)=.370, p=.713\right)$, but the two groups differed significantly for paternal emotion-related conversations $\left(M_{\mathrm{TD}}=2.24\right.$, $\left.\mathrm{SD}_{\mathrm{TD}}=.39 ; M_{\mathrm{ASD}}=1.86, \mathrm{SD}_{\mathrm{ASD}}=.74 ; t(21.349)=-1.751, p=.094\right)$. Fathers of TD children spontaneously discussed emotions with their children, encouraged them to explain what they were feeling, asked questions about emotions, explained the causes and consequences of emotions, and took time to answer their children's questions about emotion to a greater extent than fathers of ASD children. Moreover, our results indicated that neither mothers of ASD children and of TD children $\left(M_{\mathrm{TD}}=11.14, \mathrm{SD}_{\mathrm{TD}}=4.04 ; M_{\mathrm{ASD}}=11.79, \mathrm{SD}_{\mathrm{ASD}}=8.12 ; t(41.393)\right.$

Table 8. Spearman correlations between mothers' and fathers' emotion-related conversations and parents' and children's individual characteristics.

\begin{tabular}{|c|c|c|c|c|c|c|c|c|c|c|c|c|}
\hline & & \multicolumn{5}{|c|}{ Children's personality } & \multicolumn{6}{|c|}{ Openness to emotional processes } \\
\hline & & $\mathrm{E}$ & A & $\mathrm{C}$ & ES & $\mathrm{O}$ & REPCOG & COMEMO & PERINT & PEREXT & REGEMO & RESNOR \\
\hline \multirow[t]{2}{*}{ ASD sample } & $\begin{array}{c}\text { Maternal } \\
\text { emotion-related } \\
\text { conversations }\end{array}$ & .131 & -.141 & -.006 & -.099 & .275 & .028 & -.182 & -.061 & -.048 & .102 & .138 \\
\hline & $\begin{array}{c}\text { Paternal } \\
\text { emotion-related } \\
\text { conversations }\end{array}$ & .169 & -.007 & -.018 & -.281 & -.210 & -.004 & $.725^{\star \star}$ & .089 & .155 & .071 & $.534^{*}$ \\
\hline \multirow[t]{2}{*}{ TD sample } & $\begin{array}{c}\text { Maternal } \\
\text { emotion-related } \\
\text { conversations }\end{array}$ & -.190 & -.009 & .296 & .222 & -.101 & -.092 & .146 & .054 & .179 & -.274 & .067 \\
\hline & $\begin{array}{c}\text { Paternal } \\
\text { emotion-related } \\
\text { conversations }\end{array}$ & .104 & .379 & -.018 & .104 & .230 & .239 & .136 & .169 & .217 & .063 & -.183 \\
\hline
\end{tabular}

Notes: ASD = Autism Spectrum Disorders, $\mathrm{TD}=$ typically developing, $\mathrm{E}=$ Extraversion, $\mathrm{A}=$ Agreeableness, $\mathrm{C}=$ Conscientiousness, ES = Emotional stability, $\mathrm{O}=$ Openness, REPCOG = Cognitive-Conceptual Representation of Emotions, COMEMO = Communication of Emotion, PERINT $=$ Perception of Internal Bodily Indicators of Emotions, PEREXT $=$ Perception of External Bodily Indicators of Emotions, REGEMO = Regulation of Emotion, RESNOR $=$ Normative Restrictions of Affectivity, ${ }^{*} p<.05,{ }^{* *} p<.01$. 
$=-.385, p=.702)$ nor fathers of ASD children and of TD children $\left(M_{\mathrm{TD}}=\right.$ $\left.12.07, \mathrm{SD}_{\mathrm{TD}}=7.79 ; M_{\mathrm{ASD}}=10.87, \mathrm{SD}_{\mathrm{ASD}}=7.86 ; t(28)=.420, p=.678\right)$ differed significantly in the number of emotional terms that they usually used during emotion-related conversations with their children.

Variability of parental emotion-related conversations with their ASD children according to parents' and children's characteristics.

In order to explore the extent to which both individual children's and parents' characteristics could predict the variance in the scores for parental emotion-related conversations with their children, several linear regression analyses by the stepwise method were performed. We present two separate models to analyse maternal and paternal emotion-related conversations independently. For children's characteristics, we entered children's chronological age and children's global developmental age in Step 1 and scores in the five factors of personality in Step 2. Concerning parents' characteristics, we entered parents' age and level of education in Step 3, and scores in the six factors of openness to emotional processes were added in step 4. Items were evaluated for multicollinearity using the variance inflation index (VIF). In each group, for the two models (maternal and paternal), there was no multicollinearity between variables.

Maternal emotion-related conversation with their children. Table 9 presents the results of significant predictors of maternal emotion-related conversations for the two groups. For the ASD group, Model M1a, including children's extraversion, explained $25 \%$ of the variance in the number of emotional terms used by mothers during emotion-related conversations with their ASD children. For the TD group, we observe a mutual influence of children's characteristics and mothers' characteristics. Model M1b, including children's conscientiousness and extraversion and mothers' level of education, explained $44 \%$ of the variance in the score for maternal emotion-related conversations.

Table 9. Predictors of maternal emotion-related conversations.

\begin{tabular}{|c|c|c|c|c|c|c|c|c|c|c|c|}
\hline \multicolumn{6}{|c|}{ ASD sample } & \multicolumn{6}{|c|}{ TD sample } \\
\hline & & & & & & \multicolumn{6}{|c|}{ Maternal emotion-related conversations } \\
\hline & & & & & & Predictors & B & $\mathrm{SE} / \mathrm{B}$ & $\beta$ & $\mathrm{R}_{\text {adj }}^{2}$ & $F$ \\
\hline & & & & & & Model M1a & & & & & \\
\hline & & & & & & EBMCF_C & .209 & .062 & $.591^{\star *}$ & .32 & $4.941^{* *}$ \\
\hline & & & & & & EBMCF_E & -.087 & .039 & $-.392^{\star}$ & .02 & \\
\hline & & & & & & Model M1b & & & & & \\
\hline & & & & & & EBMCF_C & .208 & .056 & $.591^{\star *}$ & & \\
\hline & & & & & & EBMCF_E & -.077 & .036 & $-.345^{*}$ & .44 & $1.373^{n}$ \\
\hline & & & & & & Level of education & .142 & .057 & $.378^{\star}$ & & \\
\hline \multicolumn{12}{|c|}{ Number of emotional terms } \\
\hline Predictors & B & $\mathrm{SE} / \mathrm{B}$ & $\beta$ & $\mathrm{R}_{\text {adj }}^{2}$ & $F$ & & & & & & \\
\hline Model M1a & & & & .25 & $7.271^{*}$ & & & & & & \\
\hline EBMCF_E & 2.189 & .812 & $.536^{*}$ & & & & & & & & \\
\hline
\end{tabular}

Notes: ASD $=$ Autism Spectrum Disorders, $\mathrm{TD}=$ typically developing, EBMCF $=$ Bipolar Rating Scales based on the Five Factor Model, $\mathrm{C}=$ Conscientiousness, $\mathrm{E}=$ Extraversion, ${ }^{*} p<.05$. 
Paternal emotion-related conversations with their children. Table 10 presents the results of significant predictors of paternal emotion-related conversations for the ASD group. Model P1a, including father's abilities to perceive the external bodily indicators of emotions, explained $54 \%$ of the variance in the score for paternal emotion-related conversations. No significant result was obtained for the TD group.

\section{Discussion}

The purpose of these studies was to examine the profiles of both parents of ASD children for an important domain of parenting: the socialization of emotions. Specifically, we aimed to identify the differences in ERSBs-the way in which parents react to their children's emotions and the way in which they discuss emotions in the family-between parents of ASD children and parents of TD children. The second aim of these studies was to examine the variability of these parental ERSBs according to the characteristics of parents (age, level of education and level of openness to emotional processes) and the characteristics of ASD children (age, developmental age and personality). Although the study of Bougher-Muckian et al. (2016) provided initial information about the profile of parental reactions to their ASD children's emotions, our study has provided new data, notably by including fathers and by exploring the determinants of parental ERSBs. To our knowledge, this is the first attempt to explore ERSBs of parents of ASD children in more details.

Study 1 focused on parental reactions to their children's emotions. The results concerning the between-groups comparison found few differences between parents of ASD children and parents of TD children: mothers and fathers of ASD children comforted their children when they displayed negative emotions (anger, fear or sadness), more than parents of TD children. These results agreed with those reported in the study of Bougher-Muckian et al. (2016) and highlighted that, despite their children's specific emotional characteristics, parents of ASD children did not display more non-supportive reactions, than parents of TD children: on the contrary, they used more supportive reactions. However, it is important to note that a supportive reaction for TD children may be a nonsupportive one for ASD children: the study of Mazzone and Nader-Grosbois (accepted) showed that supportive behaviours, such as comforting reactions, may be rather a non-supportive reaction because it deprives children of an op-

Table 10. Predictors of paternal emotion-related conversations.

\begin{tabular}{cccccc}
\hline \multicolumn{5}{c}{ ASD sample } \\
& \multicolumn{5}{c}{ Paternal emotion-related conversations } \\
\hline $\begin{array}{c}\text { Predictors } \\
\text { Model P1a }\end{array}$ & $\mathrm{B}$ & $\mathrm{SE} / \mathrm{B}$ & $\beta$ & $\mathrm{R}_{\text {adj }}^{2}$ & $F$ \\
DOE_PEREXT & .610 & .178 & $.771^{* * *}$ & .54 & $11.724^{* * *}$ \\
\hline
\end{tabular}

Notes: ASD $=$ Autism Spectrum Disorders, DOE $=$ Dimensions of Openness to Emotions, PEREXT $=$ Perception of External Bodily Indicators of Emotions, ${ }^{* *} p<.00$. 
portunity to explore their feelings. Comforting reactions displayed by parents of ASD children could be a strategy of overprotection, but may not be effective as their children grow older. Such observations would be consistent with the results of a recent study suggesting that, as older children acquire more autonomy, cognitive ability and emotional competence, supportive ERSBs may not benefit them and may even inhibit their development (Mirabile, Oertwig, \& Halberstadt, 2016). We therefore need more studies to identify supportive parental ERSBs that foster ASD children's emotional development. In order to explore the predictors of maternal and paternal reactions to children's emotions, linear regression analyses by the stepwise method were tested for the two groups. Concerning mothers' reactions to their ASD children's emotions, when mothers felt limited in their emotional expression by social rules and conventions and when they had the ability to express and communicate their emotions, they displayed supportive reactions to their children's negative emotions, such as encouragement of expression of emotion and problem-focused responses. As expected, when mothers had good emotional regulation competences, they used fewer nonsupportive reactions to their children's negative and positive emotions. Moreover, they displayed fewer non-supportive reactions and more encouragement of children's positive emotions when they had a good knowledge of emotions. Finally, our results showed that ASD children's personality partially determine maternal reactions. When children were perceived as imaginative, curious and creative, mothers used more socialization responses (explaining why the behaviour may be considered socially inappropriate), while when they were perceived as meticulous, careful and organized, mothers displayed more encouragement of their ASD children's positive emotions. For the TD group, we obtained less significant results than for the ASD group. When mothers had a good knowledge of emotions and when their children were perceived as empathic and cooperative, they displayed fewer non-supportive reactions to children's positive emotions. Regarding fathers' reactions to their ASD children's emotions, when fathers had a good knowledge of emotions, they used fewer socialization responses and fewer non-supportive reactions to their children's positive emotions. Moreover, we observed that fathers' characteristics such as age and level of education predicted paternal reactions: the higher the fathers' level of education, the less they displayed non-supportive reactions to children's negative emotions, and the older they were, the less they used socialization responses. Finally, when children were perceived as imaginative, curious and creative, fathers used more socialization responses. For the TD group, only fathers' age and children's global developmental age explained paternal reactions.

Study 2 explored parental emotion related conversations in parents of ASD children and in parents of TD children. The between-group comparison revealed that there are no difference between mothers of ASD children and mothers of TD children. However, fathers of TD children spontaneously discussed emotions with their children, encouraged them to explain their feelings, asked questions about emotions, explained the causes and consequences of emotions, and took 
time to answer their children's questions about emotion more than fathers of ASD children. Given ASD children's emotional and language characteristics, it is likely that these children are less oriented toward these conversations than TD children. Therefore, fathers of ASD children have maybe some difficulties to initiate emotion-related conversations. This would be consistent with the finding of parenting studies emphasized that parent-child effects are dynamic and bidirectional (e.g., Bell, 1968; Eisenberg, Fabes, Shepard, Guthrie, Murphy, \& Reiser 1999; Parke, Ornstein, Rieser, \& Zahn-Waxler, 1994). The results for maternal emotion-related conversations revealed, in the ASD group, that children's personality, the factor of extraversion, determined the number of emotional terms used by mothers. Extravert children may be more likely to interact with others, including adults, by sharing their feelings, desires, etc. This personality trait could encourage parents to diversify emotional terms when they discuss emotions with their child. By contrast, for the TD group, children's personality and mothers' level of education determined maternal emotion-related conversations. Concerning paternal emotion-related conversations, the results for the ASD sample showed that when fathers were aware of their own external bodily indicators of emotions, they were more likely to discuss about emotions with their children. This emotional awareness allowed the fathers to be more attentive to their children's emotions, and by means of emotion-related conversations, they encouraged them to be aware of their own emotions too.

These findings indicated that parental ERSBs are predicted by both parents' and children's characteristics, specifically for the ASD group. The group comparison of the TD children, enables us to show that our findings reveal a specific characteristic of the ASD group, by contrast. The most significant result concerned the importance for parents of regulating their own emotions well, at least for mothers, and of having a good knowledge of emotions. Consistently with the meta-emotion philosophy of Gottman et al. $(1996,1997)$, our results showed that when parents were able to regulate their own emotions and when they had an extensive knowledge of emotions and in particular were able to differentiate affects, they displayed more supportive reactions and fewer non-supportive reactions. Another important result concerns the positive effect of the personality factor of openness, suggesting that when parents perceived their children as imaginative, curious and creative, they gave more explanation of why expressing positive emotions might be socially inappropriate in particular contexts. This result may be explained by the fact that children who are open to others and curious are more likely to ask questions about emotions, leading their parents to feel that they will be receptive to explanations.

Some limitations need to be considered in the present studies. One limitation was that the ASD children in our samples did not display high levels of autistic traits (the average level assessed by the CARS-T corresponded to a mild level of ASD), which means that our findings only relate to parents of ASD children with mild to moderate levels of autistic traits. Future research should investigate this topic in parents of ASD children with different levels of severity of autism. Mo- 
reover, our studies had small sample sizes and the parents had a very high socioeconomic status. Our studies should therefore be reproduced with a larger sample and with greater diversity in socioeconomic status. Despite these limitations, this study has clinical implications and practical importance for parenting by providing initial guidelines for designing an adapted parental program focusing on ERSBs for parents of ASD children. Our findings emphasize the importance of assessing parents' emotional abilities, notably their emotional regulation competences and their knowledge of emotions, for the purpose of making them aware of their own characteristics that could affect their ERSBs. Our group-specific results revealed that we need to help parents of ASD children differently from parents of TD children, notably by working on their openness to emotional processes. As ERSBs in parents of ASD children are determined by their openness to emotional processes, we can help them more effectively by assessing their level of emotional regulation abilities and their knowledge of emotions than is the case for parents of TD children. Moreover, as suggested by Barger et al. (2016), it seems important for parents to know that characteristics of their children such as personality, and not just the core features of ASD, could also affect their own behaviours. Given these implications, psychologists and clinicians should be able to assist both groups of parents comprehensively in becoming aware of these important factors to help them to effectively socialize their ASD children's emotions.

\section{References}

Barger, B., Campbell, J., \& Simmons, C. (2016). The Five Factor Personality Model in Children with ASD during Middle Childhood. Focus on Autism and Other Developmental Disabilities, 31, 1-10. https://doi.org/10.1177/1088357615583472

Bell, R. Q. (1968). A Reinterpretation of the Direction of Effects in Studies of Socialization. Psychological Review, 75, 83-96. https://doi.org/10.1037/h0025583

Belsky, J. (1984). The Determinants of Parenting: A Process Model. Child Development, 55, 83-96. https://doi.org/10.2307/1129836

Belsky, J. (1997). Theory Testing, Effect-Size Evaluation, and Differential Susceptibility to Rearing Influence: The Case of Mothering and Attachment. Child Development, 68, 598-600. https://doi.org/10.1111/j.1467-8624.1997.tb04221.x

Bougher-Muckian, H. R., Root, A. E., Coogle, C. G., \& Floyd, K. K. (2016). The Importance of Emotions: The Socialisation of Emotion in Parents of Children with Autism Spectrum Disorder. Early Child Development and Care, 186, 1584-1593.

https://doi.org/10.1080/03004430.2015.1112799

Coutu, S., Dubeau, D., Provost, M. A., Royer, N., \& Lavigueur, S. (2002). Validation de la version française du questionnaire: Coping with Children's Negative Emotions ScaleCCNES. Canadian Journal of Behavioural Science/Revue Canadienne des Sciences du Comportement, 34, 230-234. https://doi.org/10.1037/h0087175

Daffe, V., \& Nader-Grosbois, N. (2009). Réactions parentales face aux émotions de leur enfant: Adaptation intégrée de deux instruments. In N. Nader-Grosbois (Ed.), Résilience, régulation et qualité de vie: Concepts, évaluation et intervention (pp. 143159). Louvain-la-Neuve: Presses Universitaires de Louvain.

Darling, N., \& Steinberg, L. (1993). Parenting Style as Context: An Integrative Model. Psychological Bulletin, 113, 487-496. 
https://doi.org/10.1037/0033-2909.113.3.487

De Pauw, S. S. W., Mervielde, I., Van Leeuwen, K. G., \& De Clercq, B. J. (2011). How Temperament and Personality Contribute to the Maladjustment of Children With Autism. Journal of Autism and Developmental Disorders, 41, 196-212. https://doi.org/10.1007/s10803-010-1043-6

Denham, S. A., \& Auerbach, S. (1995). Moderators of Gender Effects on Parents' Talk to Their Children: A Meta-Analysis. Genetic, Social \& General Psychology Monographs, 121, 313.

Durrleman, S., Burnel, M., Thommen, E., Foudon, N., Sonié, S., Reboul, A., \& Fourneret, P. (2016). The Language Cognition Interface in ASD: Complement Sentences and False Belief Reasoning. Research in Autism Spectrum Disorders, 21, 109-120.

Eisenberg, N., Cumberland, A., \& Spinrad, T. L. (1998). Parental Socialization of Emotion. Psychological Inquiry, 9, 241-273. https://doi.org/10.1207/s15327965pli0904_1

Eisenberg, N., Fabes, R. A., \& Murphy, B. C. (1996). Parents' Reactions to Children's Negative Emotions: Relations to Children's Social Competence and Comforting Behavior. Child Development, 67, 2227-2247. https://doi.org/10.1111/j.1467-8624.1996.tb01854.x

Eisenberg, N., Fabes, R. A., Shepard, S. A., Guthrie, I. K., Murphy, B. C., \& Reiser, M. (1999). Parental Reactions to Children's Negative Emotions: Longitudinal Relations to Quality of Children's Social Functioning. Child Development, 70, 513-534. https://doi.org/10.1111/1467-8624.00037

Fabes, R. A., Poulin, R. E., Eisenberg, N., \& Madden-Derdich, D. A. (2002). The Coping with Children's Negative Emotions Scale (CCNES): Psychometric Properties and Relations with Children's Emotional Competence. Marriage \& Family Review, 34, 285-310. https://doi.org/10.1300/J002v34n03_05

Firth, I., \& Dryer, R. (2013). The Predictors of Distress in Parents of Children with Autism Spectrum Disorder. Journal of Intellectual \& Developmental Disability, 38, 163 171. https://doi.org/10.3109/13668250.2013.773964

Garner, P. W., Dunsmore, J. C., \& Southam-Gerrow, M. (2008). Mother-Child Conversations about Emotions: Linkages to Child Aggression and Prosocial Behavior. Social Development, 17, 259-277. https://doi.org/10.1111/j.1467-9507.2007.00424.x

Gottman, J. M., Katz, L. F., \& Hooven, C. (1996). Parental Meta-Emotion Philosophy and the Emotional Life of Families: Theoretical Models and Preliminary Data. Journal of Family Psychology, 10, 243-268. https://doi.org/10.1037/0893-3200.10.3.243

Gottman, J. M., Katz, L. F., \& Hooven, C. (1997). Meta-Emotion: How Families Communicate Emotionally. Mathway, NJ: Erlbaum.

Havighurst, S. S., Wilson, K. R., Harley, A. E., \& Prior, M. R. (2009). Tuning in to Kids: An Emotion-Focused Parenting Program-Initial Findings from a Community Trial. Journal of Community Psychology, 37, 1008-1023. https://doi.org/10.1002/jcop.20345

Herbert, S. D., Harvey, E. A., Roberts, J. L., Wichowski, K., \& Lugo-Candelas, C. I. (2013). A Randomized Controlled Trial of a Parent Training and Emotion Socialization Program for Families of Hyperactive Preschool-Aged Children. Behavior Therapy, 44, 302316.

Jahromi, L. B., Bryce, C. I., \& Swanson, J. (2013). The Importance of Self-Regulation for the School and Peer Engagement of Children with High-Functioning Autism. Research in Autism Spectrum Disorders, 7, 235-246.

Kay-Raining Bird, E., Cleave, P. L., Curia, J., \& Dunleavy, M. (2008). Parental Talk about Internal States to Their Child with Autism. Focus on Autism and Other Developmental Disabilities, 23, 166-175. https://doi.org/10.1177/1088357608319530 
Ladouceur, C., Reid, L., \& Jacques, A. (2002). Construction et validation du Questionnaire sur les réactions parentales aux émotions positives exprimées par l'enfant. Canadian Journal of Behavioural Science, 34, 8-18. https://doi.org/10.1037/h0087150

Lagattuta, K. H., \& Wellman, H. M. (2002). Differences in Early Parent-Child Conversations about Negative versus Positive Emotions: Implications for the Development of Psychological Understanding. Developmental Psychology, 38, 564-580.

https://doi.org/10.1037/0012-1649.38.4.564

Li, J., Zhu, L., Liu, J., \& Li, X. (2014). Social and Non-Social Deficits in Children with High-Functioning Autism and Their Cooperative Behaviors. Research in Autism Spectrum Disorders, 8, 1657-1671.

Maljaars, J., Boonen, H., Lambrechts, G., Van Leeuwen, K., \& Noens, I. (2014). Maternal Parenting Behavior and Child Behavior Problems in Families of Children and Adolescents with Autism Spectrum Disorder. Journal of Autism and Developmental Disorders, 44, 501-512. https://doi.org/10.1007/s10803-013-1894-8

Mazzone, S., \& Nader-Grosbois, N. (2016). How Are Parental Reactions to Children's Emotions Related to Their Theory of Mind Abilities? Psychology, 7, 166-179. https://doi.org/10.4236/psych.2016.72019

Mazzone, S., \& Nader-Grosbois, N. (accepted). How Are Parental Reactions to Children's Emotions Linked with Theory of Mind in Children with Autism Spectrum Disorder. Research in Autism Spectrum Disorders.

Mazzone, S., Roskam, I., Mikolajczak, M., \& Nader-Grosbois, N. (2017). Do Parents Talk about Emotions with Their Children? The Questionnaire of Parent-Child Conversations about Emotions (QPCCE). Psychology, 8, 987-1007. https://doi.org/10.4236/psych.2017.87065

McElwain, N. L., Halberstadt, A. G., \& Volling, B. L. (2007). Mother- and Father-Reported Reactions to Children's Negative Emotions: Relations to Young Children's Emotional Understanding and Friendship Quality. Child Development, 78, 1407-1425. https://doi.org/10.1111/j.1467-8624.2007.01074.x

Mirabile, S. P., Oertwig, D., \& Halberstadt, A. G. (2016). Parent Emotion Socialization and Children's Socioemotional Adjustment: When Is Supportiveness No Longer Supportive? Social Development. https://doi.org/10.1111/sode.12226

Morris, A. S., Silk, J. S., Steinberg, L., Myers, S. S., \& Robinson, L. R. (2007). The Role of the Family Context in the Development of Emotion Regulation. Social Development, 16, 361-388. https://doi.org/10.1111/j.1467-9507.2007.00389.x

Nader-Grosbois, N., \& Mazzone, S. (2014). Emotion Regulation, Personality and Social Adjustment in Children with Autism Spectrum Disorders. Psychology, 5, 1750-1767. https://doi.org/10.4236/psych.2014.515182

Ontai, L. L., \& Thompson, R. A. (2002). Patterns of Attachment and Maternal Discourse Effects on Children's Emotion Understanding from 3 to 5 Years of Age. Social Development, 11, 433-450. https://doi.org/10.1111/1467-9507.00209

Ozturk, Y., Riccadonna, S., \& Venuti, P. (2014). Parenting Dimensions in Mothers and Fathers of Children with Autism Spectrum Disorders. Research in Autism Spectrum Disorders, 8, 1295-1306.

Parke, R. D., Ornstein, P. A., Rieser, J. J., \& Zahn-Waxler, C. (1994). The Past as Prologue: An Overview of a Century of Developmental Psychology. In R. D. Parke, P. A. Ornstein, J. J. Rieser, \& C. Zahn-Waxler (Eds.), A Century of Developmental Psychology (pp. 1-75). Washington DC: American Psychological Association.

Perron-Borelli, M. (1996). Echelles Différentielles d'Efficiences Intellectuelles. Forme 
révisée (EDEI-R). Paris: Editions et applications psychologiques.

Perry, N. B., Calkins, S. D., Nelson, J. A., Leerkes, E. M., \& Marcovitch, S. (2012). Mothers' Responses to Children's Negative Emotions and Child Emotion Regulation: The Moderating Role of Vagal Suppression. Developmental Psychobiology, 54, 503-513. https://doi.org/10.1002/dev.20608

Peters-Scheffer, N., Didden, R., Korzilius, H., \& Matson, J. (2012). Cost Comparison of Early Intensive Behavioral Intervention and Treatment as Usual for Children with Autism Spectrum Disorder in the Netherlands. Research in Developmental Disabilities, 33, 1763-1772.

Prinzie, P., Onghena, P., Hellinckx, W., Grietens, H., Ghesquière, P., \& Colpin, H. (2004). Parent and Child Personality Characteristics as Predictors of Negative Discipline and Externalizing Problem Behaviour in Children. European Journal of Personality, 18, 73 102. https://doi.org/10.1002/per.501

Reicherts, M. (2007). Dimensions of Openness to Emotion (DOE): A Model of Affect Processing, Manual. Fribourg: Department of Psychology, University of Fribourg.

Rivers, J. W., \& Stoneman, Z. (2008). Child Temperaments, Differential Parenting, and the Sibling Relationships of Children with Autism Spectrum Disorder. Journal of Autism and Developmental Disorders, 38, 1740-1750. https://doi.org/10.1007/s10803-008-0560-Z

Roskam, I., de Maere-Gaudissart, A., \& Vandenplas-Holper, C. (2000). The Point of an Instrument to Evaluate Personality in Children Using the Five-Factor Model. Orientation Scolaire et Professionnelle, 29, 661-672.

Ruffman, T., Slade, L., \& Crowe, E. (2002). The Relation between Children's and Mothers' Mental State Language and Theory-of-Mind Understanding. Child Development, 73, 734-751. https://doi.org/10.1111/1467-8624.00435

Sanders, M. R., Mazzucchelli, T. G., \& Studman, L. J. (2004). Stepping Stones Triple P: The Theoretical Basis and Development of an Evidence-Based Positive Parenting Program for Families with a Child Who Has a Disability. Journal of Intellectual \& Developmental Disability, 29, 265-283. https://doi.org/10.1080/13668250412331285127

Schopler, E., Reichler, R. J., DeVellis, R. F., \& Daly, K. (1980). Toward Objective Classification of Childhood Autism: Childhood Autism Rating Scale (CARS). Journal of Autism and Developmental Disorders, 10, 91-103. https://doi.org/10.1007/BF02408436

Shewark, E. A., \& Blandon, A. Y. (2015). Mothers' and Fathers' Emotion Socialization and Children's Emotion Regulation: A Within-Family Model. Social Development, 24, 266-284. https://doi.org/10.1111/sode.12095

Slaughter, V., Peterson, C. C., \& Mackintosh, E. (2007). Mind What Mother Says: Narrative Input and Theory of Mind in Typical Children and Those on the Autism Spectrum. Child Development, 78, 839-858. https://doi.org/10.1111/j.1467-8624.2007.01036.x

Zingerevich, C., \& Patricia D, L. (2009). The Contribution of Executive Functions to Participation in School Activities of Children with High Functioning Autism Spectrum Disorder. Research in Autism Spectrum Disorders, 3, 429-437. 


\section{Appendix}

Categorization of supportive and non-supportive reactions (Mazzone \& Nader-Grosbois, 2016)

\begin{tabular}{|c|c|c|c|}
\hline & Categorization & Authors & $\begin{array}{l}\text { Description of parents' behavior toward their } \\
\text { child }\end{array}$ \\
\hline \multirow{4}{*}{ SR } & $\begin{array}{l}\text { Problem-focused } \\
\text { responses }\end{array}$ & $\begin{array}{c}\text { Coutu, Dubeau, Provost, Royer, \& Lavigueur, } \\
\text { 2002; Fabes et al., } 2002\end{array}$ & $\begin{array}{l}\text { Helping to solve the problem that caused the } \\
\text { child's distress }\end{array}$ \\
\hline & Socialization & Ladouceur, Reid \& Jacques, 2002 & $\begin{array}{l}\text { Explaining why the behavior may be considered } \\
\text { socially inappropriate }\end{array}$ \\
\hline & Comforting & Coutu et al., 2002; Fabes et al., 2002 & $\begin{array}{l}\text { Helping the child to feel better by comforting or } \\
\text { distracting }\end{array}$ \\
\hline & Encouragement & $\begin{array}{l}\text { Coutu et al., 2002; Fabes et al., 2002; } \\
\text { Ladouceur et al., } 2002\end{array}$ & $\begin{array}{c}\text { Showing their acceptance of the child's emotional } \\
\text { displays by encouraging him/her to express } \\
\text { emotions }\end{array}$ \\
\hline \multirow{5}{*}{ NSR } & Minimizing & Coutu et al., 2002; Fabes et al., 2002 & $\begin{array}{l}\text { Denying the seriousness of emotional reactions } \\
\text { or devaluing the problem }\end{array}$ \\
\hline & Distress & Coutu et al., 2002; Fabes et al., 2002 & $\begin{array}{l}\text { Becoming powerless in response to an emotion } \\
\text { and displaying emotional distress }\end{array}$ \\
\hline & Discomfort & Ladouceur et al., 2002 & Feeling embarrassed by an emotional display \\
\hline & Avoidance/Dismissing & Ladouceur et al., 2002 & Avoiding contact \\
\hline & Punitive/Reprimanding & $\begin{array}{l}\text { Coutu et al., 2002; Fabes et al., 2002; } \\
\text { Ladouceur et al., } 2002\end{array}$ & Punishing to control the emotional display \\
\hline
\end{tabular}

Notes: $\mathrm{SR}=$ supportive reactions, NSR = non-supportive reactions.

\section{Submit or recommend next manuscript to SCIRP and we will provide best} service for you:

Accepting pre-submission inquiries through Email, Facebook, LinkedIn, Twitter, etc. A wide selection of journals (inclusive of 9 subjects, more than 200 journals)

Providing 24-hour high-quality service

User-friendly online submission system

Fair and swift peer-review system

Efficient typesetting and proofreading procedure

Display of the result of downloads and visits, as well as the number of cited articles

Maximum dissemination of your research work

Submit your manuscript at: http://papersubmission.scirp.org/

Or contact psych@scirp.org 